\title{
A pooled analysis of risk factors of surgically treated leiomyosarcoma of the colon in adults
}

\author{
Yun Wang ${ }^{1,2+}$, Hao Wang ${ }^{3 \dagger}$, Zhi-Lu Yuan ${ }^{4}$, Jing-Fei Zhao ${ }^{4}$, Dian-Bo Dong ${ }^{5}$ and Qian Gao ${ }^{1 *}$
}

\begin{abstract}
Background: This current systematic review aimed to evaluate the role of surgical management and risk factors by pooled cases from all identified patients with colonic leiomyosarcomas.

Methods: The authors searched the Ovid MEDLINE, Embase, PubMed, and Cochrane databases using the keywords "colonic," "colon," and "leiomyosarcoma." Risk factors of colonic leiomyosarcoma in the pooled cohort were also evaluated.

Results: Between 1923 and 2019, 41 cases of colonic leiomyosarcoma were identified in 22 (53.7\%) males and 19 (46.3\%) females, with a mean and median age of $58.7 \pm 2.2$ years and 56.0 years. According to univariate analysis, smaller tumor size $<8 \mathrm{~cm}$ was significantly associated with longer progression-free survival $(\mathrm{HR}=6.957,95 \% \mathrm{Cl}$ $1.405-34.442 ; p=0.017)$, and younger age $<60$ years was trending toward better overall survival $(H R=2.765,95 \%$ Cl 0.924-8.272; $p=0.069$ ).
\end{abstract}

Conclusions: Colonic leiomyosarcomas are rare neoplasms with aggressive clinical behaviors. Age $<60$ years and tumor size $<8 \mathrm{~cm}$ were favorable factors for patients' better survival.

Keywords: Leiomyosarcoma of the colon, Prognostic factors, Treatment

\section{Introduction}

In 1923, Scott firstly reported one case of colonic leiomyosarcoma (CLMS) [1]. Gastrointestinal LMS of the colon, an uncommon condition that accounts for less than $1 \%$ of all colorectal malignancies, has a strong propensity to recur and to metastasize at distant sites (liver and lung) [2]. Surgery and adjuvant chemotherapy have been used in the treatment of CLMS patients. But given the rarity of this tumor, there was no clear information about the risk factors following therapeutic strategy. Therefore, we performed an extensive literature review, and this current

\footnotetext{
* Correspondence: qhgaog@126.com

${ }^{\dagger}$ Yun Wang and Hao Wang contributed equally to this work.

'Department of Digestive System, Qinghai University Affiliated Hospital, Xining 810000, Qinghai, China

Full list of author information is available at the end of the article
}

systematic review aimed to evaluate the role of surgical management and risk factors by pooled cases from all identified patients with CLMS [2-29].

\section{Methods \\ Literature search strategy}

The search protocol, including the search questions and inclusion and exclusion criteria, was developed a priority according to the Preferred Reporting Items for systematic reviews and meta-analysis (PRISMA) guidelines. We performed a systematic literature research of the Ovid Medline, Embase, Pubmed, and Cochrane Library Database from 1923 to 2019. The keywords used in the search were "colonic," "colon," and "leiomyosarcoma." We further reviewed all the references provided in the publication and incorporate 
the pertinent citations. Language was limited to English. The process was shown in Fig. 1.

\section{Case eligibility criteria}

Inclusion criteria for literature cases were as follows: (1) adult patients ( $\geq 18$ years of age) with a diagnosis of CLMS who underwent surgery; (2) availability of overall survival (OS) data. Exclusion criteria for literature cases were as follows: (1) studies published in a language other than English; (2) unavailable patient data; (3) basic research rather than clinical report without clinical data; (4) patients have developed a distant metastasis before or at surgery; (5) patients died of other causes.

\section{Study eligibility and data extraction}

Two investigators independently and in duplicate performed title and abstract screening of the studies in the search query results. Discrepancies between the review authors over the bias in studies were resolved by discussing with a third reviewer (Q.G) when needed. The following data were extracted from each study whenever possible: author and year of published articles, patient characteristics (gender and age), tumor size, treatment strategy, primary tumor gross appearance, duration of follow-up, progression-free survival (PFS), and OS. Due to incomplete and limited patients' status for recurrence and metastasis, we defined PFS for both local and distant recurrence.

\section{Statistical analysis}

Mean values are presented with their standard deviation (SD). The primary outcome of CLMS was PFS and OS, and its pertinent adverse factors were evaluated by univariate analysis. Due to the small number of patients, we did not perform multivariate Cox regression analysis. Outcomes were PFS and OS in subgroups with significant risk factors and their pertinent estimated PFS and OS time performed using the Kaplan-Meier method. All analyses were performed using IBM SPSS (version 25.0, IBM Corp.) with significance set at $p<0.05$.

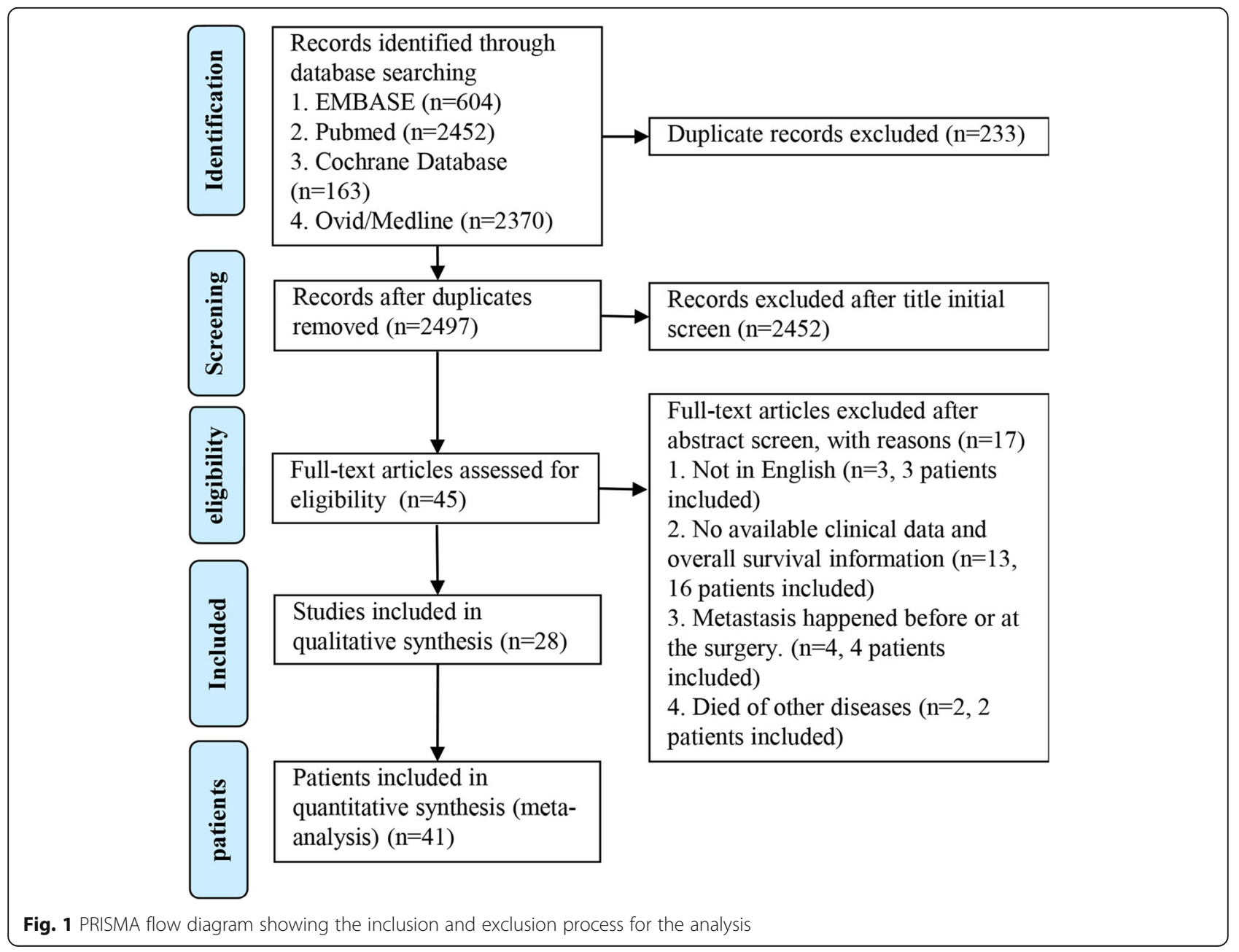




\section{Results}

\section{Data from literature cases}

From the period between 1923 and 2019, 41 cases of CLMS were identified in 22 (53.7\%) males and 19 (46.3\%) females, with a mean and median age of $58.7 \pm$ 2.2 years and 56.0 years; respectively. The most common preoperative symptoms were abdominal pain $(n=15$, $36.6 \%)$, followed by abdominal mass $(n=5,12.2 \%)$, rectal bleeding $(n=3,7.3 \%)$, bloody stool $(n=3,7.3 \%)$, occlusion $(n=2,4.9 \%)$, anemia $(n=2,4.9 \%)$, lower gastrointestinal bleeding $(n=1,2.4 \%)$, drowsiness $(n=$ $1,2.4 \%)$, alternating constipation $(n=1,2.4 \%)$, and asymptomatic $(n=1,2.4 \%)$. Tumor size was identified in 31 patients, ranging from 1.0 to $30.0 \mathrm{~cm}$, with a mean and median size of $9.1 \pm 1.2 \mathrm{~cm}$ and $7.8 \mathrm{~cm}$, respectively. The gross appearance was identified in 23 patients. The most frequent appearance was polypoid $(n=8,34.8 \%)$, followed by intramural $(n=5,21.7 \%)$, type $2(n=4$, $17.3 \%)$, exophytic $(n=2,8.7 \%)$, pedunculate $(n=1$, $4.3 \%)$, plaque $(n=1,4.3 \%)$, sessile $(n=1,4.3 \%)$, and subserosal $(n=1,4.3 \%)$. Five patients in prior studies underwent open partial colectomy. No patients received radiotherapy prior to or after surgery. Only 2 (4.9\%) patients underwent adjuvant chemotherapy after surgery (Table 1).

\section{Survival}

In prior studies, patients' status $(n=11)$ about recurrence and metastasis were not available. Four patients developed recurrence, and 7 patients happened to distant metastasis. The PFS rates of 30 patients with CLMS at 1,3 , and 5 years from the time of diagnosis were $74.6 \%, 50.2 \%$, and $50.2 \%$, respectively (Fig. $2 a$ ). The mean PFS was $79.0 \pm 15.9$ months. The OS rates of the entire series of patients with CLMS $(n=41)$ at 1,3 , and 5 years from the time of the diagnosis were $81.6 \%, 60.8 \%$, and $45.6 \%$, respectively (Fig. 2b), and the mean OS was 95.5 \pm 18.6 months (Table 2).

According to univariate analysis, smaller tumor size < $8 \mathrm{~cm}$ was significantly associated with improved PFS $(\mathrm{HR}=6.957,95 \%$ CI 1.405-34.442; $p=0.017)$ (Fig. 3a), and younger age $<60$ years was associated with better OS $(\mathrm{HR}=2.765,95 \%$ CI 0.924-8.272; $p=0.069)$ (Fig. 3b) (Table 2).

\section{Discussion}

CLMSs are extremely rare neoplasms, and most of them have been described as case reports. In the past, LMS of the colon's prognosis has been generally considered to be a benign tumor that displayed optimism with a low propensity for recurrence and distant metastasis [1, 30]. Later on, literature reported that frequent recurrences and distant metastasis have been observed in the CLMS [31]. Due to the paucity of data about CLMS, the information regarding its clinical characteristics and specific treatment was still unclear. Based on prior studies, we identified influencing risk factors for PFS and OS after surgical treatment, and aimed to increase the better understanding of this type of tumor.

LMS of the colon is slightly more frequent in males. Rao BK et al. reviewed 42 cases with CLMS that female dominance was found in his study [11]. The mean age in this study at the time of diagnosis was 56 years old, which is older than that in a literature review that reported a mean age at diagnosis of 50 years old [13]. Meanwhile, we found that older people had a decreased OS.

Based on the only complains and physical examinations, it is difficult to make an identified diagnosis of CLMS because preoperative symptoms, such as pain, diarrhea, and constipation, are insufficient evidence to make a diagnose of CLMS [12]. LMS could be exactly confirmed by the expression of smooth muscle actin and lack of CD117 [32].

Warkel et al. reported that survival of patients with the CLMS was not associated with the tumor size, but with mitotic activity [31]. In contrast, our study indicated that larger tumor size was associated with worsened PFS. One previous study consistent with our study advocated significant association between large tumor size and poor survival [33]. Unfortunately, with unavailable and incomplete data regarding mitotic activity, we failed to identify the relationship between mitotic activity and survival.

Surgery had been generally considered as the first line treatment for patients with CLMS. EH Ng et al. [34] published a review of 191 patients treated with surgery, and those who underwent complete resection has 25 months longer OS (the median time) than those with incomplete. In our series, due to the lack of details about the type of resection in the operative report of resection, we were unable to find significant difference in PFS or OS rates among patients who received different surgical treatments.

One finding of concerns in this study was the extremely high metastasis rate, and the most frequent sites of distant locations mainly in the liver, lung, peritoneum, humerus, and viscera. Even, many reviewers reported that CLMS with an aggressive clinical behavior that tends to high recurrence and metastasis after radical surgery [33, 35]. Seven patients developed distant metastasis in this current review study, in addition, many patients have developed metastasis before they underwent surgery. Patients with a distant metastasis in general had a poor survival. Therefore, adjuvant treatment after surgery might be recommended in patients with malignant tumors. To the Best of Our Knowledge, however, no postoperative radiotherapy for LMS of the colon has 


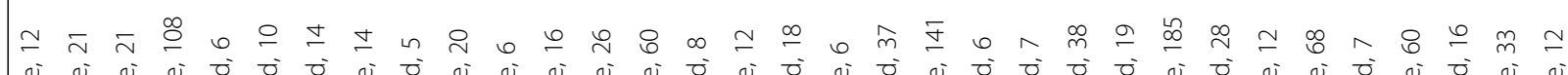

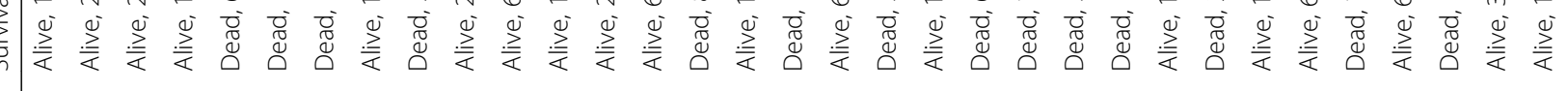





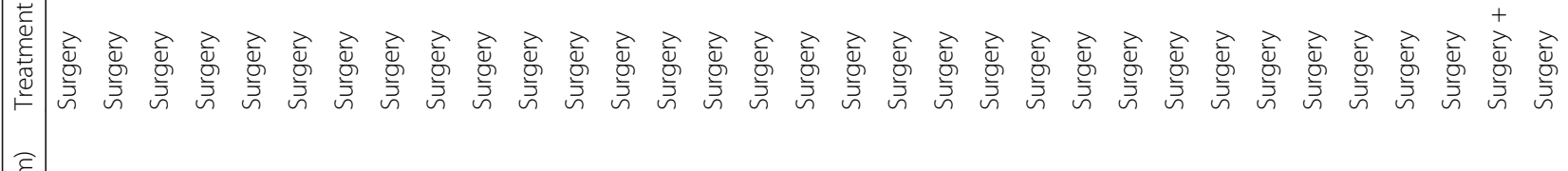

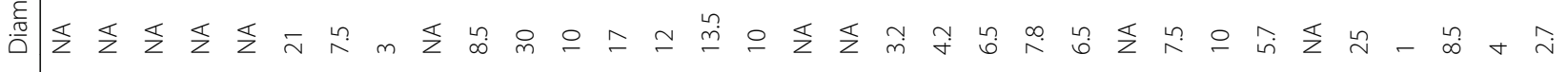

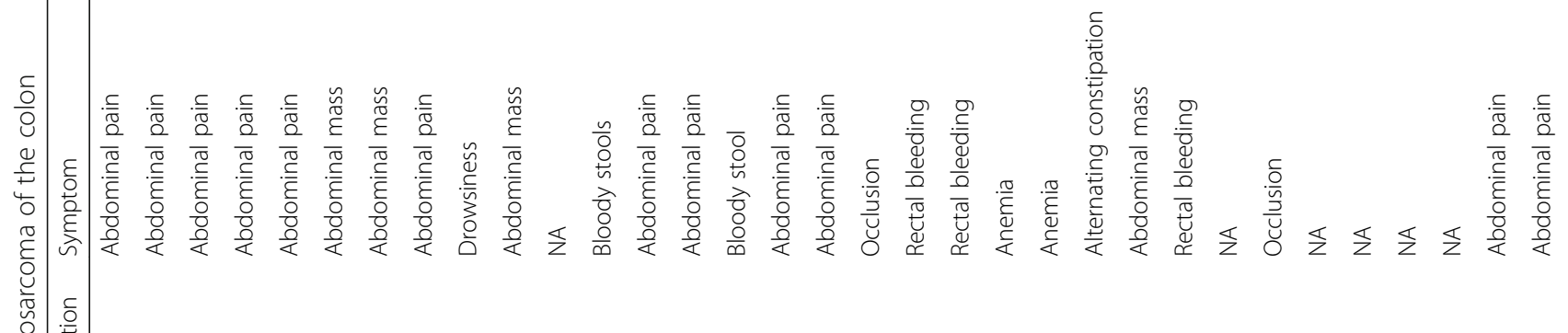



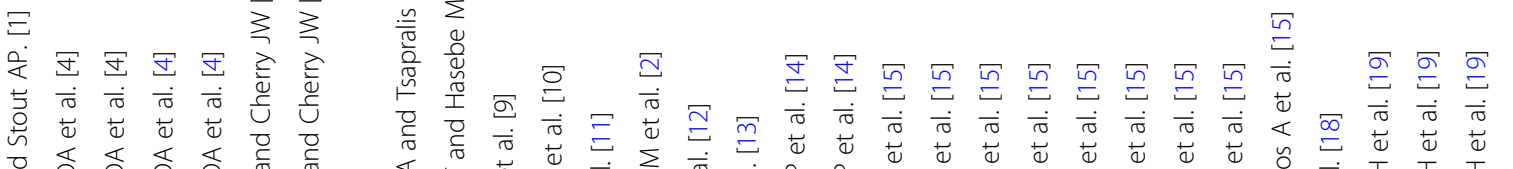

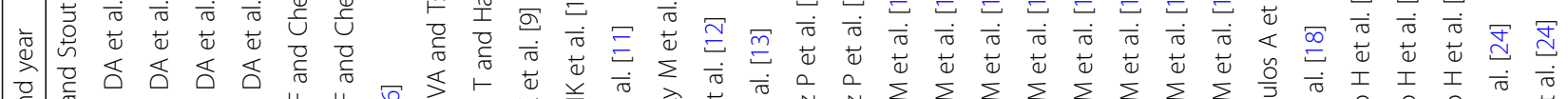

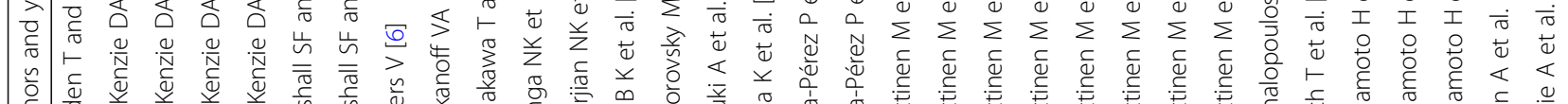

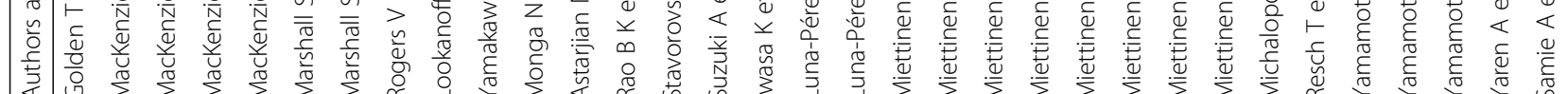

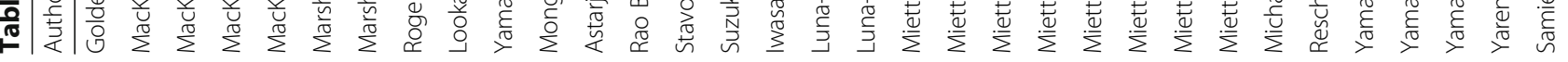








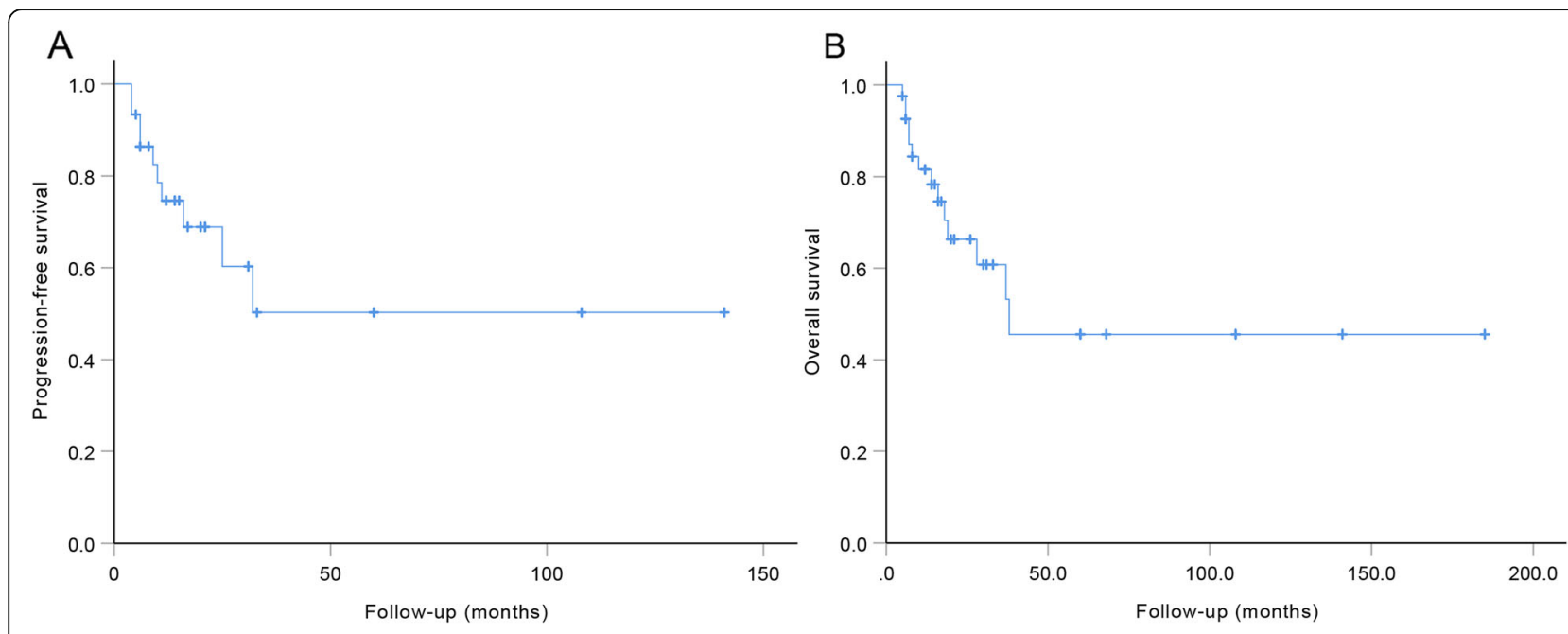

Fig. 2 a PFS rates. b OS rates

been reported yet. Adjuvant chemotherapy has been described in only two studies, with mixed results. Yaren A et al. [20] reported that a 66-year-old female with CLMS underwent adjuvant chemotherapy with ifosfamide plus doxorubicin after surgery, and no evidence of disease was observed during his follow-up time. Kiran $\mathrm{P}$ et al. [23] reported that a 54-year old male with LMS of the colon received postoperative chemotherapy with ifosfamide and doxorubicin for six cycles, but then he developed a recurrence after a disease-free period of half a

Table 2 Clinical data and survival in literature cases

\begin{tabular}{|c|c|c|c|c|c|c|c|}
\hline \multirow[t]{2}{*}{ Variable } & \multirow[t]{2}{*}{$n(\%)$} & \multicolumn{2}{|c|}{ Progression-free survival* (\%) } & \multirow[t]{2}{*}{$p$ value } & \multicolumn{2}{|c|}{ Overall survival (\%) } & \multirow[t]{2}{*}{$p$ value } \\
\hline & & 1 year & 3 year & & 1 year & 3 year & \\
\hline Gender & & & & $0.554^{\dagger}$ & & & $0.252^{+}$ \\
\hline Male & $22(53.7)$ & 68.6 & 45.8 & & 85.9 & 66.2 & \\
\hline Female & $19(46.3)$ & 83.1 & 54.5 & & 76.7 & 54.9 & \\
\hline Age, yrs & & & & $0.560^{\dagger}$ & & & $0.129^{\dagger}$ \\
\hline$\geq 60$ & $17(41.5)$ & 80.0 & 60.0 & & 76.5 & 31.1 & \\
\hline$<60$ & $24(58.5)$ & 71.5 & 44.7 & & 85.3 & 78.7 & \\
\hline Tumor size $(\mathrm{cm})$ & & & & $0.045^{\dagger \ddagger}$ & & & $0.602^{\dagger \S}$ \\
\hline Range & $1-30$ & & & & & & \\
\hline$\geq 8.0$ & $15(51.7)$ & 49.4 & 18.5 & & 76.2 & 33.3 & \\
\hline$<8.0$ & $14(48.3)$ & 91.7 & 68.8 & & 80.0 & 72.0 & \\
\hline Tumor location & & & & - & & & - \\
\hline Ascending & $13(31.7)$ & 87.5 & 32.8 & & 83.9 & 62.9 & \\
\hline Transverse & $9(22.0)$ & 85.7 & 85.7 & & 87.5 & 87.5 & \\
\hline Descending & $5(12.2)$ & 33.3 & 33.3 & & 60.0 & 40.0 & \\
\hline Sigmoid & $9(22.0)$ & 85.7 & 42.9 & & 88.9 & 55.6 & \\
\hline Cecum & $5(12.2)$ & 33.3 & 33.3 & & 80.0 & 53.3 & \\
\hline Reports period & & & & $0.350^{\dagger}$ & & & $0.594^{\dagger}$ \\
\hline 1923-1999 & $18(43.9)$ & 91.7 & 52.4 & & 76.2 & 58.8 & \\
\hline 2000-2019 & $23(56.1)$ & 63.6 & 47.7 & & 85.9 & 64.9 & \\
\hline
\end{tabular}

Bold means $p<0.05$

*Eleven patients were excluded

${ }^{\dagger}$ Chi-square test

‡Seventeen patients were excluded

${ }^{\S}$ Ten patients were excluded 

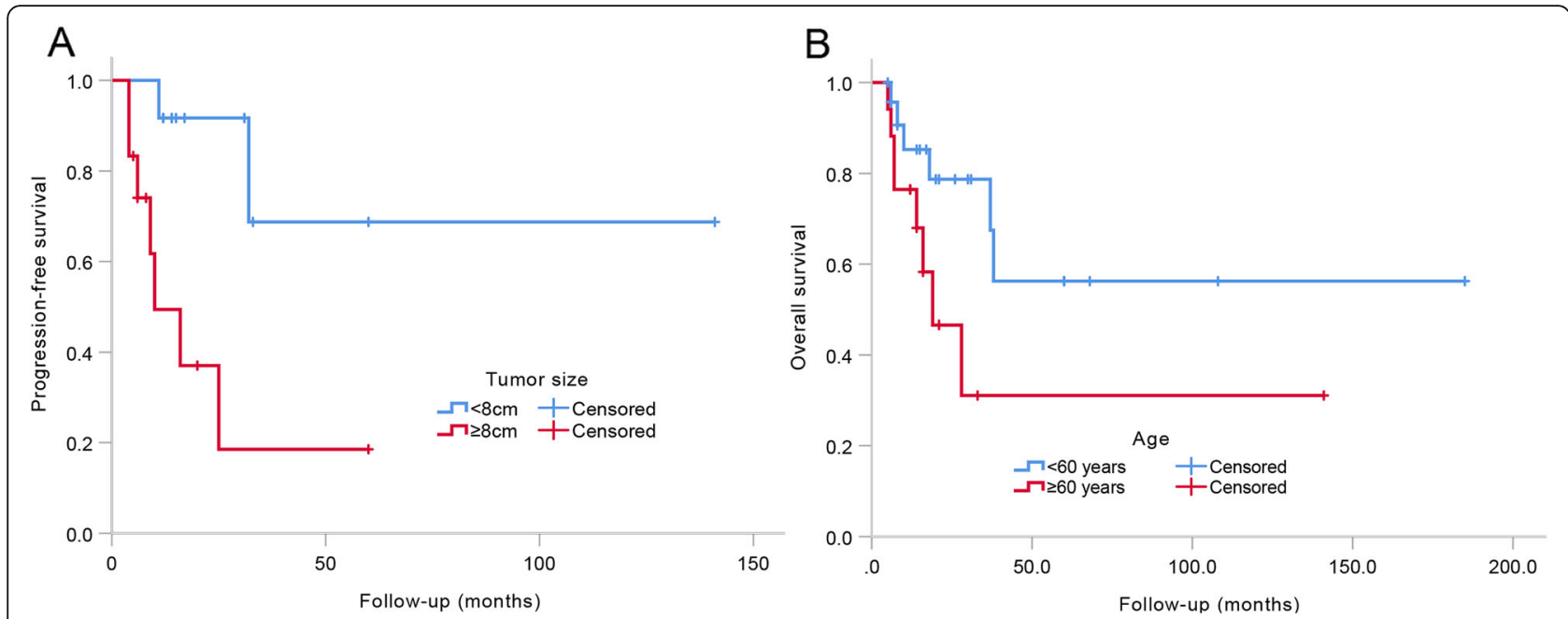

Fig. 3 a Different PFS between tumor size $<8 \mathrm{~cm}$ and tumor size $\geq 8 \mathrm{~cm}$. b Different OS between age $<60$ years and age $\geq 60$ years

year. After a surgery for recurrence, he was still alive well without disease. With the two better results described, adjuvant chemotherapy following surgery might be optimal for patients with large LMS of the colon. However, we could not definitely confirm the role of it because of inadequate follow-up time and limited cases. Longer follow-up could be performed to identify the effect of adjuvant treatment.

\section{Limitations}

The limitations of this study were as follows: (1) the major was its retrospective nature, and selection bias always played a role; (2) the assessment methods of surgical management were undetailed described among studies, and we were unable to define which type of surgery did favor to increased survival; 3 ) we did not give an identified answer to a question whether better survival was beneficial from adjuvant therapy.

\section{Conclusions}

CLMS are rare neoplasms with aggressive clinical behaviors, with a mean OS of $95.5 \pm 18.6$ months. Some potential risk factors were associated with worse survival; younger age $\geq 60$ years and tumor size $\geq 8 \mathrm{~cm}$ were associated with patients' decreased survival. Surgery followed by chemotherapy is recommended as the optimal treatment for CLMS. Given the rarity of this tumor, a prospective multiple-center randomized control trial should be performed.

\section{Abbreviations}

CLMS: Colonic leiomyosarcoma; LMS: Leiomyosarcoma; OS: Overall survival; PFS: Progression-free survival; SD: Standard deviation

\section{Acknowledgements}

No

\section{Authors' contributions}

Conceptualization: Yun Wang and Hao Wang. Data curation: Yun Wang and Hao Wang. Formal analysis: Yun Wang, Hao Wang and Qian Gao. Software: Zhi-Lu Yuan and Jing-Fei Zhao. Supervision: Qian Gao. Validation: Dian-Bo Dong. Writing —original draft: Yun Wang and Qian Gao. Writing-review and editing: Yun Wang and Qian Gao. The author(s) read and approved the final manuscript.

Funding

No

Availability of data and materials

Not applicable.

Ethics approval and consent to participate

Approved by the Ethics Committee of Qinghai University Affiliated Hospital.

\section{Consent for publication}

We have consent for publication from the patient.

\section{Competing interests}

No.

\section{Author details}

${ }^{1}$ Department of Digestive System, Qinghai University Affiliated Hospital, Xining 810000, Qinghai, China. ${ }^{2}$ Qinghai University, Xining 810000, Qinghai, China. ${ }^{3}$ Department of Intensive Care Medicine, Qinghai Province People's Hospital, Xining 810007, China. ${ }^{4}$ Department of General Surgery, Liao Cheng The Third People's Hospital, Liaocheng 252000, Shandong, People's Republic of China. ${ }^{5}$ Department of Anorectal Medicine, Liao Cheng People's Hospital, Liaocheng 252000, Shandong, People's Republic of China.

Received: 27 February 2020 Accepted: 19 March 2020

Published online: 28 March 2020

\section{References}

1. Scott CR. Myoma malignum particularly other than uterine. Northwest Med. 1923:22:436-9.

2. Stavorovsky M, Jaffa AJ, Papo J, Baratz M. Leiomyosarcoma of the colon and rectum. Dis Colon Rectum. 1980;23:249-54.

3. Golden T, Stout AP. Smooth muscle tumors of the gastrointestinal tract and retroperitoneal tissues. Surg Gynecol Obstet. 1941;73:784-810.

4. MacKenzie DA, McDonald JR, Waugh JM. Leiomyoma andleiomyosarcoma of the colon. Ann Surg. 1954;139:67-75.

5. Marshall SF, Cherry JW. Smooth muscle tumors of the alimentary canal. Surg Clin North Am. 1955;35:719-33. 
6. Rogers V. Leiomyosarcoma of the colon. Br J Radiol. 1961;34:748-50.

7. Lookanoff VA, Tsapralis PC. Smooth-muscle tumors of the colon. Report of a case involving the cecum and ascending colon. Jama. 1966;198:206.

8. Yamakawa T, Hasebe M. Leiomyosarcoma of the transverse colon: case report. Gastroenterol Jpn. 1975;10:77-9.

9. Monga NK, Sood S, Malik AK, Kaushik SP. Leiomyosarcoma of the colon. Int Surg. 1976;61:226-7.

10. Astarjian NK, Tseng CH, Keating JA, Koo BY, Reynoso G. Leiomyosarcoma of the colon: report of a case. Dis Colon Rectum. 1977;20:139.

11. Rao BK, Kapur MM, Roy S. Leiomyosarcoma of the colon: a case report and review of literature. Dis Colon Rectum. 1980;23:184-90.

12. Suzuki A, Fukuda S, Tomita S, et al. An unusual case of colonic leiomyosarcoma presenting with fever. Gastroenterologia Japonica. 1984;19: 486-92.

13. Iwasa K, Taniguchi K, Noguchi M, Yamashita H, Kitagawa M. Leiomyosarcoma of the colon presenting as acute suppurative peritonitis. Surg Today. 1997:27:337-44.

14. Luna-Pérez P, Rodríguez DF, Luján L, et al. Colorectal sarcoma: analysis of failure patterns. J Surg Oncol. 2015:69:36-40.

15. Miettinen $M$, Furlong $M$, Sarlomorikala $M$, et al. Gastrointestinal stromal tumors, intramural leiomyomas, and leiomyosarcomas in the rectum and anus: a clinicopathologic, immunohistochemical, and molecular genetic study of 144 cases. Am J Surg Pathol. 2001;25:1121-33.

16. Luigi I, Dolores DV, Giuseppe C, et al. Malignant gastrointestinal leiomyosarcoma and gastrointestinal stromal tumor with prominent osteoclast-like giant cells. Arch Pathol Lab Med. 2004;128:440-3.

17. Michalopoulos A, Papadopoulos VN, Basdanis G, et al. Colorectal gastrointestinal mesenchymal tumours. Report of a stromal case of the rectum (GIST) and a leiomyosarcoma of the transverse colon. Techniques in Coloproctology. 2004;8:s155-7.

18. Resch T, Oberhuber R, Zitt M, et al. Leiomyosarcoma of the colon: unresolved issues of a rare but highly aggressive malignancy. Am Surg. 2011;77:62-4.

19. Yamamoto $H$, Handa M, Tobo $T$, Setsu N, Fujita $K$, Oshiro $Y$, et al. Clinicopathological features of primary leiomyosarcoma of the gastrointestinal tract following recognition of gastrointestinal stromal tumours. Histopathology. 2013;63(2):194-207.

20. Yaren A, Deä Irmencioä Lu S, Callä DN, et al. Primary mesenchymal tumors of the colon: a report of three cases. Turk J Gastroenterol. 2014;25:314-8.

21. Samie AA, Sun R, Fayyazi A, Theilmann L. Leiomyosarcoma of the sigmoid colon: a rare cause of intestinal intussusception. Journal of Gastrointestinal Cancer. 2013;45:6-09.

22. Kono M, Tsuji N, Ozaki N, et al. Primary leiomyosarcoma of the colon. Clin J Gastroenterol. 2015;8:217.

23. Kiran P, Shiny PM, Dhanya KS, Aravindan KP. Diagnosis of leiomyosarcoma of colon. Journal of Cancer Research \& Therapeutics. 2015;11:1035.

24. Janevski V, Selmani R, Janevska V, et al. Leiomyosarcoma of the colon. Med Pregl. 2015;68(11-12):413-7.

25. Kim VM, Goicochea L, Fang SH. Case report: collision tumour of colon leiomyosarcoma and adenocarcinoma. Journal of Clinical \& Diagnostic Research Jcdr. 2016;10:D3.

26. Akutsu D, Mizokami Y, Suzuki $H$, et al. A rare case of colonic leiomyosarcoma in association with ulcerative colitis. Intern Med. 2016; 55:2799-803.

27. Yang J. Primary leiomyosarcoma in the colon: a case report. Medicine. 2018; 97:e9923.

28. Devriendt S, Leman G, Vanrykel F. Primary leiomyosarcoma of the colon: a case report and review of the literature. Acta Chir Belg 2019 2019-03-18: 1-4.

29. Stavorovsky M, Jaffa AJ, Papo J, Baratz M. Leiomyosarcoma of the colon and rectum [J]. Dis Colon Rectum. 1980;23(4):249-54.

30. Buxton RW. Smooth muscle tumors of the gastrointestinal tract. Am Surg. 1960;26:666.

31. Warkel RL, Stewart JB, Temple AJ. Leiomyosarcoma of the colon: report of a case and analysis of the relationship of histology to prognosis. Dis Colon Rectum. 1975;18:501-6.

32. Miettinen M, Sarlomo-Rikala M, Lasota J. Gastrointestinal stromal tumors: recent advances in understanding of their biology. Hum Pathol. 1999;30: 1213-20.

33. Kimura $\mathrm{H}$, Yonemura $\mathrm{Y}$, Kadoya $\mathrm{N}$, et al. Prognostic factors in primary gastrointestinal leiomyosarcoma: A retrospective study. World J Surg. 1991; 15:771.
34. Ng EH, Pollock RE, Munsell MF, Atkinson EN, Romsdahl MM. Prognostic factors influencing survival in gastrointestinal leiomyosarcomas. Implications for surgical management and staging. Ann Surg. 1992;215:68-77.

35. Clary BM, Dematteo RP, Lewis JJ, Leung D, Brennan MF. Gastrointestina stromal tumors and leiomyosarcoma of the abdomen and retroperitoneum: a clinical comparison. Ann Surg Oncol. 2001:8:290-9.

\section{Publisher's Note}

Springer Nature remains neutral with regard to jurisdictional claims in published maps and institutional affiliations.
Ready to submit your research? Choose BMC and benefit from:

- fast, convenient online submission

- thorough peer review by experienced researchers in your field

- rapid publication on acceptance

- support for research data, including large and complex data types

- gold Open Access which fosters wider collaboration and increased citations

- maximum visibility for your research: over $100 \mathrm{M}$ website views per year

At BMC, research is always in progress.

Learn more biomedcentral.com/submissions 